\title{
TIPOS \\ DE LINEARIZAÇÃO \\ TÓPICA \\ NA GRAMÁTICA \\ TEXTUAL-INTERATIVA
}

TIPOS DE SECUENCIACIÓN TÓPICA EN LA GRAMÁTICA TEXTUAL-INTERACTIVA

TYPES OF TOPIC SEQUENCING IN TEXTUAL-INTERACTIVE GRAMMAR

Eduardo Penhavel*

Aline Gomes Garcia**

Universidade Estadual Paulista

RESUMO: No presente artigo, focalizamos o processo de Organização Tópica, um dos processos de construção do texto distinguidos pela Gramática Textual-Interativa, quadro teórico-metodológico em que o trabalho se insere. Mais especificamente, tratamos de uma parte da Organização Tópica, a saber, a linearização tópica, que consiste no encadeamento das unidades textuais chamadas de "Segmentos Tópicos mínimos". Discutimos a tipologia de formas de linearização tópica proposta por Jubran (2006), avaliando em que medida essa tipologia é adequada para a análise de outros dois gêneros textuais (narrativa de experiência e descrição) diferentes do gênero contemplado no trabalho da autora (conversação espontânea). A esse respeito, procuramos mostrar que a referida tipologia, em linhas gerais, é adequada para a análise desses outros gêneros e procuramos demonstrar, por outro lado, a relevância da inclusão de algumas especificações nessa tipologia.

PALAVRAS-CHAVE: Organização Tópica. Tópico Discursivo. Sequenciamento Tópico.

RESUMEN: En este artículo, que está en el marco teórico de la Gramática Textual-Interactiva, nos fijamos en el proceso de Organización Tópica, uno de los procesos de construcción textual investigados en este marco. Particularmente, reflexionamos sobre una parte de la Organización Tópica, la secuenciación tópica, que es el encadenamiento de las unidades textuales conocidas como “Segmentos Tópicos mínimos". Discutimos la tipología de formas de secuenciación tópica propuesta por Jubran (2006), evaluando como esa tipología es adecuada para el análisis de otros dos géneros textuales (narrativa de experiencia y descripción) distintos de lo investigado en el trabajo de la autora (conversación espontánea). Sobre eso, buscamos enseñar que dicha tipología, de manera general, es adecuada para analizar esos otros géneros, e intentamos demostrar, por otro lado, la importancia de añadir algunas especificaciones en esta tipología.

PALABRAS-CLAVE: Organización Tópica. Tópico Discursivo. Secuenciación Tópica.

\footnotetext{
* Doutor em Linguística. Professor da Universidade Estadual Paulista (UNeSP), campus de São José do Rio Preto, SP

E-mail: penhavel@ibilce.unesp.br.

** Mestranda em Estudos Linguísticos na Universidade Estadual Paulista (UNESP), campus de São José do Rio Preto, SP E-mail: aline.ggarcia@hotmail.com.
} 
ABSTRACT: This paper is developed within the theoretical framework of Textual-Interactive Grammar, and it focuses on the process of Topic Organization, which is one of the text construction processes studied within that approach. A specific part of the Topic Organization process is analyzed, namely the topic sequencing process, which concerns the concatenation of the units called "minimal Topic Segments". The discussion addresses the typology of topic-sequencing strategies proposed by Jubran (2006), in order to evaluate to what extent her classification is adequate for the analysis of two genres (narrative of experience and description) that are different from the one initially considered in her proposal (spontaneous conversation). In this respect, the purpose of this paper is to demonstrate that the typology proposed by the author is in fact adequate for the analysis of these two other genres. Yet, it is also argued that such typology should incorporate further subcategories.

KEYWORDS: Topic Organization. Discourse Topic. Topic Sequencing.

\section{INTRODUÇÃO}

Entre a década de 1970 e o início dos anos 2000, foi desenvolvido no Brasil um projeto coletivo de pesquisa na área dos estudos linguísticos intitulado "Projeto de Gramática do Português Falado" (CASTILHO, 1990). No interior desse projeto, um grupo de pesquisadores foi discutindo e definindo uma série de conceitos e princípios analíticos para estudo do texto, chegando, ao final do projeto, à formulação de uma abordagem teórico-metodológica para análise textual, que ficou conhecida como "Perspectiva Textual-Interativa”, ou “Gramática Textual-Interativa”, sistematizada principalmente em Jubran \& Koch (2006) e Jubran (2007).

Desde o término do projeto, a Gramática Textual-Interativa (doravante GTI) vem sendo aplicada, por vários pesquisadores, à investigação de uma grande diversidade de fenômenos textuais e vem passando por um minucioso processo de aprimoramento de conceitos teóricos e de procedimentos de análise, assim como por um processo de ampliação de seu escopo, sendo expandida de uma abordagem mais especializada no estudo de certos gêneros textuais (principalmente falados, conforme sua tendência original) para uma abordagem válida para os gêneros textuais em geral (inclusive para gêneros escritos). O presente trabalho insere-se nesse empreendimento de aplicação e consolidação de pressupostos e procedimentos da GTI.

A GTI considera que a atividade de construção do texto é norteada por um processo central, denominado de "Organização Tópica". Esse processo consiste na organização (divisão) do texto em partes e subpartes de natureza textual, chamadas de "Segmentos Tópicos" (SegTs). Os menores SegTs de um texto são denominados de "SegTs mínimos” e correspondem, grosso modo, a trechos textuais equivalentes a um, dois, três parágrafos no caso, por exemplo, de certos gêneros escritos. Uma parte da Organização Tópica diz respeito ao processo de linearização tópica, que é o encadeamento (sequenciamento) de SegTs mínimos no decorrer do texto, um após o outro. Jubran (2006), com base em Jubran et al. (2002), distingue, então, um conjunto de tipos específicos de transição entre SegTs mínimos, o que configura uma tipologia de estratégias de linearização tópica. No presente artigo, discutimos essa tipologia.

Tal tipologia foi formulada principalmente com base em uma situação particular de interação verbal, constituinte do corpus do Projeto de Gramática do Português Falado, a saber, o diálogo entre dois informantes, situação similar ao gênero textual conversação espontânea ${ }^{1}$. Diante disso, uma questão que nos parece pertinente e relevante envolve investigar em que medida as categorias distinguidas na tipologia de Jubran (2006) seriam adequadas considerando gêneros textuais diferentes do previsto inicialmente pela autora. Mais especificamente, esse questionamento envolve avaliar se as categorias da tipologia também ocorreriam em outros gêneros textuais ou se, na verdade, seriam categoriais mais típicas do gênero abarcado no trabalho inicial da autora. De forma complementar, a questão envolve avaliar se as categorias da tipologia, caso não estejam, de fato, circunscritas apenas ao gênero contemplado pela autora, seriam suficientes para descrever a diversidade de formas de linearização de SegTs mínimos encontradas em outros gêneros. Ainda, a questão compreende verificar se a investigação de outros gêneros não revelaria particularidades não

\footnotetext{
${ }^{1}$ No corpus do Projeto de Gramática do Português Falado, a situação de diálogo entre dois informantes assemelha-se ao gênero conversação espontânea. Para os propósitos do presente artigo, não chega a ser crucial discutir em que medida essa situação de interação verbal constitui propriamente um gênero textual. Assim, consideramos que essa situação contempla um gênero particular, ou corresponde a um gênero - a conversação espontânea. Essa aproximação é aqui suficiente para nosso objetivo de submeter a tipologia de Jubran (2006) a dados diferentes dos analisados pela autora e avaliar, assim, a possibilidade de generalização da tipologia como uma classificação válida para a língua em geral, e não apenas para uma dada situação específica.
} 
previstas pela autora no funcionamento dessas categorias.

Neste artigo, desenvolvemos uma análise de dois gêneros textuais particulares, diferentes daquele contemplado no trabalho de Jubran (2006), focalizando exatamente esses questionamentos. Analisamos textos dos gêneros narrativa de experiência e descrição, extraídos do Banco de Dados IBORUNA (GONÇALVES, 2007). O objetivo do artigo é, então, verificar se a tipologia proposta por Jubran é adequada para a análise desses outros dois gêneros textuais. Desse modo, procuramos oferecer dados que possam contribuir para se pensar sobre o poder de generalização da tipologia formulada pela autora.

O artigo encontra-se organizado da seguinte forma: na próxima seção, apresentamos uma síntese da GTI, do processo de Organização Tópica e da tipologia de formas de linearização tópica; na sequência, desenvolvemos uma discussão de dados para expor nossa avaliação sobre a tipologia em foco; finalmente, apresentamos a seção de conclusões.

\section{A GTI, A ORGANIZAÇÃO TÓPICA E A TIPOLOGIA DE FORMAS DE LINEARIZAÇÃO TÓPICA}

A GTI fundamenta-se em uma série de conceitos e princípios teórico-metodológicos. Dentre eles, destacam-se a concepção de língua como interação social, o princípio de que os fenômenos textuais têm suas propriedades e funções definidas nas situações concretas de interlocução, coenvolvendo as circunstâncias enunciativas, e o princípio de que os fatores interacionais não constituem apenas uma moldura dentro da qual se processam os fenômenos linguístico-textuais, isto é, não são externos ao texto e apenas ligados a ele, mas são fatores constitutivos do texto e inerentes à expressão linguística (JUBRAN, 2007).

Com base principalmente nesses pressupostos, a GTI seleciona o texto como objeto de estudo, focalizando, em particular, a atividade de construção do texto, isto é, a atividade, interacionalmente orientada, de combinação de (grupos de) enunciados para a construção total do texto. A GTI considera que a construção do texto é regida por um processo central, a Organização Tópica, reconhecendo ainda que outros seis processos - a saber, Referenciação, Parafraseamento, Repetição, Correção, Parentetização e Tematização/Rematização - atuam de forma direta e regular junto à Organização Tópica, sendo também considerados como processos de construção do texto. Assim, o programa de pesquisa da GTI compreende o estudo desses processos de construção textual, assim como o estudo de um conjunto de expressões linguísticas que atuam no gerenciamento textual-interativo desses processos, os chamados Marcadores Discursivos. Como mencionado acima, o fenômeno aqui em análise - a linearização de SegTs mínimos - é parte do processo de Organização Tópica.

A Organização Tópica pode ser definida como a organização do texto mediante a construção e articulação hierárquica e linear de grupos de enunciados formulados pelos interlocutores a respeito de conjuntos de referentes concernentes entre si e em relevância em determinados pontos do texto (JUBRAN, 2006; KOCH, BENTES \& REZENDE, 2006; PINHEIRO, 2003, 2005). Como postula essa definição, o processo compreende, portanto, dois procedimentos essenciais: (i) a construção de grupos de enunciados tematicamente concernentes entre si e em relevância em certos pontos do texto (grupos que constituem os SegTs do texto); (ii) a combinação entre SegTs, o que inclui a articulação tópica hierárquica (ou seja, o estabelecimento de relações de superordenação e subordenação entre SegTs segundo o grau de abrangência dos assuntos que abordam) e a articulação tópica linear (que, como mencionado, consiste na linearização, ou sequenciamento, de SegTs mínimos).

Jubran (2006) apresenta uma tipologia de formas de linearização entre SegTs mínimos. A autora distingue três principais formas: (i) continuidade tópica; (ii) descontinuidade tópica; (iii) outras formas de linearização tópica. A continuidade é o processo pelo qual um novo SegT mínimo é introduzido após o desenvolvimento completo do SegT mínimo anterior. Nesse caso, a abertura de um novo SegT ocorre somente após o fechamento do SegT que o precede, isto é, o novo SegT é introduzido apenas no momento em que os interlocutores registram, de alguma forma, uma finalização do SegT precedente no que diz respeito a seu desenvolvimento temático.

A descontinuidade decorre de uma perturbação da sequencialidade linear. São distinguidas três formas de descontinuidade: (i) ruptura tópica; (ii) cisão tópica; (iii) expansão tópica. A ruptura tópica ocorre quando um tópico é introduzido, mas não chega 
realmente a se desenvolver e constituir um SegT mínimo, porque outro tópico é introduzido, interrompendo o anterior. Nesse caso, o tópico que sofre a ruptura, ou seja, aquele que não chega a se desenvolver, não volta a aparecer no texto.

A cisão tópica consiste na separação de um SegT mínimo em partes, de modo que suas partes não estejam organizadas de forma adjacente na linearidade do texto. Ou seja, o SegT mínimo é desenvolvido de forma descontínua. São distinguidas duas formas de cisão: (i) inserção tópica; (ii) alternância tópica. A inserção caracteriza-se pela divisão de um SegT mínimo em partes não contíguas segundo um esquema $A B A$, em que um SegT mínimo $A$ é interrompido por um SegT mínimo $B$ e, após o desenvolvimento completo de $B, A$ volta a ser desenvolvido e concluído. Ou seja, ocorre a inserção de um SegT no interior de outro. Já a alternância caracteriza-se por uma espécie de revezamento entre SegTs mínimos, segundo um esquema $A B A B$. Nesse caso, um SegT mínimo $A$ é interrompido por um SegT $B$, posteriormente $A$ é retomado, interrompe $B$ e é concluído, e por fim $B$ é também retomado e concluído. Há, assim, uma interpolação entre dois SegTs mínimos.

A expansão tópica ocorre quando alguns dados anunciados de passagem em determinado ponto do texto são, mais tardiamente, focalizados e desenvolvidos de modo a constituir um SegT mínimo. Nesse caso, verifica-se descontinuidade entre a primeira menção a esses dados e seu desenvolvimento posterior na forma de um SegT mínimo.

Além da continuidade e da descontinuidade, Jubran (2006) distingue outras formas específicas de linearização: (i) transição tópica; (ii) superposição tópica; (iii) movimento tópico. A transição tópica ocorre quando os interlocutores constroem um SegT mínimo dedicado a fazer a transição temática entre dois SegTs (isto é, entre o SegT anterior e o posterior ao SegT de transição). A superposição pode ocorrer quando há a tentativa de introdução de um novo SegT mínimo. Nesse caso, enquanto um falante ainda está desenvolvendo um SegT, seu interlocutor tenta introduzir outro SegT, de modo que os dois ocorram simultaneamente em certo ponto da interação. Já o movimento constitui um caso peculiar, em que dois ou mais SegTs mínimos adjacentes desenvolvem, cada um, um aspecto particular de um mesmo tema mais geral. Nesse caso, de um SegT para outro, os interlocutores "deslizam" de um aspecto para outro de um mesmo tema comum.

A tipologia proposta por Jubran (2006) pode ser sintetizada no esquema em (1):

(1) Tipologia de formas de linearização tópica proposta por Jubran (2006):

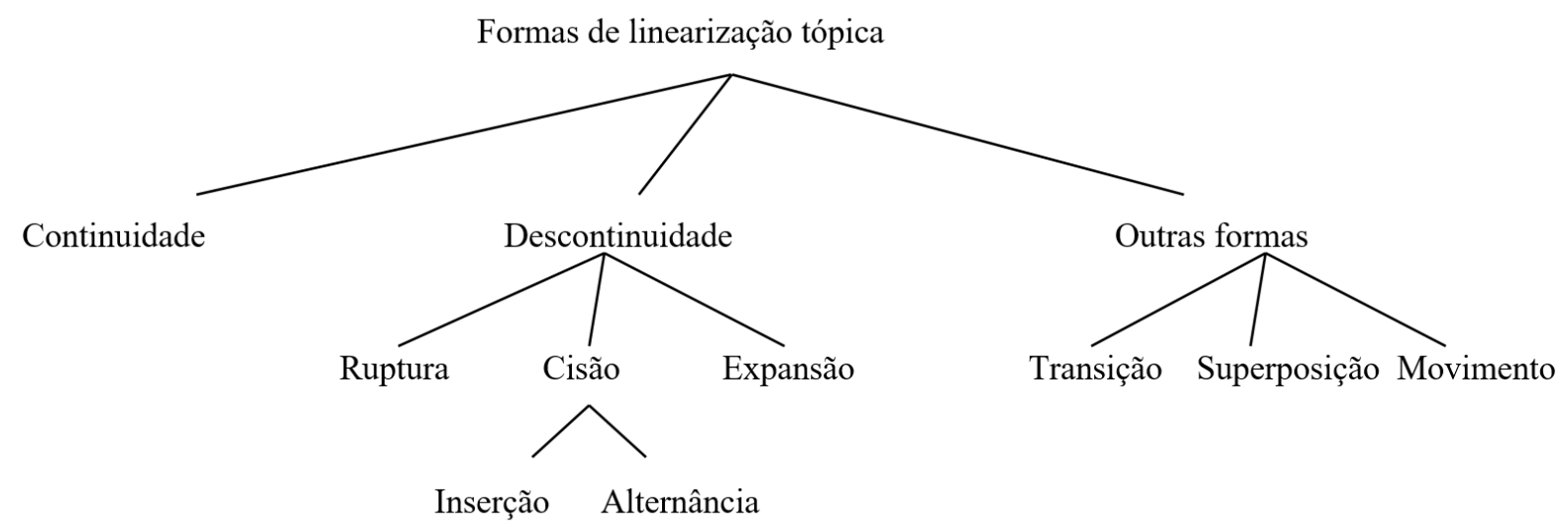

No restante do artigo, procuramos, então, avaliar essa tipologia. 


\section{FORMAS DE LINEARIZAÇÃO TÓPICA EM NARRATIVAS E DESCRIÇÕES E CONTRIBUIÇÕES PARA A GTI}

Nesta seção, discutimos dados extraídos de narrativas de experiência e descrições para analisar a tipologia de formas de linearização tópica proposta por Jubran (2006). A seleção desses dois gêneros se deve ao fato de o presente trabalho estar inserido num projeto de pesquisa maior (PENHAVEL, 2013) que tem como objetivo estudar o processo de Organização Tópica em gêneros textuais variados, contemplando, no momento, justamente os dois gêneros aqui em foco. Essa pesquisa mais ampla selecionou o Banco de Dados IBORUNA (GONÇALVES, 2007) por considerar que ele oferece uma variedade satisfatória de gêneros textuais, incluindo, além de narrativas de experiência e descrições, os gêneros narrativa recontada, relato de procedimento, relato de opinião e conversação espontânea. O Banco contém amostras de fala de parte da região noroeste do estado de São Paulo, recolhidas de informantes selecionados com base em critérios sociolinguísticos, como faixa etária, sexo e grau de escolaridade. Para o presente trabalho foram selecionadas doze narrativas de experiência e doze descrições, escolhidas de modo a recobrir a diversidade de tipos de informantes constituintes do Banco de Dados. Além dessas razões, a seleção de narrativas de experiência e descrições é, de fato, condizente com os propósitos deste artigo na medida em que se trata de gêneros consideravelmente diferentes do contemplado na pesquisa inicial de Jubran (2006).

Conforme explicado, o objetivo deste trabalho é verificar se a tipologia de formas de linearização tópica proposta por Jubran (2006) é adequada para a análise dos gêneros narrativa de experiência e descrição. A esse respeito, nossos dados indicam que a referida tipologia constitui, sim, em linhas gerais, uma proposta adequada também para esses dois gêneros. Nesta seção, discutimos, então, esse resultado.

Nosso entendimento de que a tipologia em pauta constitui, em linhas gerais, uma proposta adequada decorre da constatação de que, na análise dos dois gêneros aqui em foco, as categorias da tipologia se mostraram suficientes (requerendo, no entanto, algumas especificações) e quase todas essas categorias foram necessárias. Essa constatação, em boa parte, pode ser detectada na tabela abaixo, que mostra resultados obtidos em nossa análise:

Tabela 1: Tipos e quantitativos de estratégias de linearização tópica em narrativas e descrições.

\begin{tabular}{|c|c|c|}
\hline $\begin{array}{c}\text { Tipos de estratégias de linearização tópica distinguidos } \\
\text { por Jubran (2006) }\end{array}$ & $\begin{array}{l}\text { Ocorrências em narrativas de } \\
\text { experiência }\end{array}$ & Ocorrências em descrições \\
\hline Continuidade tópica & $93,44 \%$ (57 casos) & $79,50 \%$ (62 casos) \\
\hline Descontinuidade por ruptura tópica & $1,64 \%(1$ caso $)$ & $7,69 \%$ (6 casos) \\
\hline Descontinuidade por inserção tópica & $3,28 \%$ ( 2 casos $)$ & $8,97 \%$ ( 7 casos $)$ \\
\hline Descontinuidade por alternância tópica & $0 \%(0$ casos $)$ & $1,28 \%$ ( 1 caso $)$ \\
\hline Descontinuidade por expansão tópica & $1,64 \%$ ( 1 caso $)$ & $2,56 \%(2$ casos $)$ \\
\hline Transição tópica & $0 \%(0$ casos $)$ & $0 \%(0$ casos $)$ \\
\hline Sobreposição tópica & $0 \%(0$ casos $)$ & $0 \%(0$ casos $)$ \\
\hline Movimento tópico & $0 \%(0$ casos $)$ & $0 \%(0$ casos $)$ \\
\hline Total & $100 \%(61$ casos $)$ & $100 \%(78$ casos $)$ \\
\hline
\end{tabular}

Antes de prosseguirmos com a discussão dos dados dessa tabela, trazemos abaixo exemplos que ilustram os tipos de linearização encontrados em nosso corpus, começando com o exemplo em (2), extraído de uma narrativa de experiência, que representa um caso de continuidade tópica: 


\section{(2) [SegT mínimo 1]}

ah na verdade eu vô(u) vô(u) contá(r)... de como eu conheci a minha... minha mulher... éh:.... éh que eu acho razoavelmente interessante assim a história porque:.... a família dela se mudô(u) pra pra Guapiaçu... e:: o... PAI dela éh conheceu meu pai numa relação de trabalho (...) o pai dela acabava:: por... usá(r) o telefone na minha casa e ia/ ia na minha casa pra usá(r) o telefone... e às vezes ele ia com a família... (...) eles freqüentavam minha casa assim éh:: algumas vezes... e.: até um/ até uma certa idade quando ela tinha uns dez anos e depois... eu nunca mais a vi assim a/ sumiu... da minha vida e eu:: num/ nem me lembrava mais que existia esse pessoal tal... porque passô $(\mathrm{u})$ muito tempo realmente...

\section{[SegT mínimo 2]}

e aí quando eu tinha::... vinte anos... né? quando eu tinha vinte anos... éh:: em um/ em uma boate eu acabei esbarrando com ela e::/ e a gente... se conheceu assim... por mais que ela tivesse já dezesseis Anos aí quando a última vez que eu tinha visto acho que ela devia tê(r) uns oito ou dez anos... me lembrei mais ou menos das feições dela... e aí a gente começô(u) a conversá(r) (.... $)^{2}($ Banco de Dados IBORUNA: AC-083; NE: L. 3-24). ${ }^{3}$

Nesse exemplo, o SegT $T^{4} 1$ está centrado no tópico “Amizade com a família da esposa na infância”. Após desenvolver esse tópico e lhe atribuir um tom de fechamento, o informante introduz novo tópico, que seria "O reencontro, na juventude, com a futura esposa". Como a introdução do novo tópico ${ }^{5}$ ocorre apenas após o encerramento do anterior, tem-se aí um caso de continuidade tópica.

O exemplo em (3), retirado de um texto do gênero descrição, ilustra um caso de descontinuidade por ruptura tópica:

\section{(3) [SegT mínimo 1]}

Doc.: mas... lá tá dividido em:: como? tem a parte do escritório e tem como que é? Inf.: ah lá tem a parte do escriTÓrio... que trabalha::... quatro fun/ é cinco funcionária né?... cinco seis... éh:: quatro mulher... o o um hom/ um:: um homem... éh:.... tem::... tem a secretária tem a::... a o(u)tra que mexe com:.... c'as nota fiscal lá o:....

[SegT mínimo 2]

tem na o(u)tra parte tem dois que trabalha na serra...

\section{[SegT mínimo 3]}

é:: a o(u)tra parte... é o riscadô(r) tem três riscadô(r) cada riscadô(r) trabalha duas pessoa... esse riscadô(r) a a pessoa tem que buscá::(r)... o papelão lá na na:.... lá no depósito sabê(r) a medida dele pa trazê(r) no riscadô(r)... o riscadô(r) éh:: PAssa esse::... esse papelão no na máquina... que vai pa impressora

\section{[SegT mínimo 4]}

a impressora.... aonde que trabalha mais duas pessoa... e lá eles pega e::... e e e coloca o emblema da das firma que::... que vai sê:::(r)... colocada nas ca(i)xa né?... tipo assim é mó/ MÓveis é:.... igual aqui em Mi/ Mirassol Móveis (Febel) eles coloca Móveis (Febel) a o(u)tra é Móveis (Gelus) então eles tão/ eles têm o..... os (a)preparo lá que é a:.... que eles colocam na/ na/ nos papelão lá... (Banco de Dados IBORUNA: AC-129; DE: L. 156-168).

\footnotetext{
${ }^{2}$ Em todos os exemplos aqui analisados, o uso do sinal de reticências dentro de parênteses indica a supressão de trechos do original não relevantes para as análises aqui feitas (o uso simples de reticências, sem parênteses, indica pausa na fala).

${ }^{3}$ Em todos os exemplos, a referência ao banco de dados é feita da seguinte forma: “AC” indica o tipo de amostra de fala (no caso, Amostra Censo); o número seguinte refere-se ao inquérito; as siglas "DE" e "NE" indicam, respectivamente, os gêneros descrição e narrativa de experiência; e os últimos números indicam as linhas de início e fim do exemplo na transcrição das amostras de fala no banco de dados.

${ }^{4}$ No decorrer desta seção, sempre que nos referirmos a "SegT", estaremos nos reportando à ideia de "SegT mínimo", especificação nem sempre repetida apenas por razões estilísticas.

${ }^{5}$ O termo "tópico discursivo" (ou simplesmente "tópico"), na GTI, refere-se ao tema (assunto) interacionalmente construído pelos interlocutores num determinado ponto do texto.
} 
No exemplo em (3), o informante descreve a fábrica onde trabalha. Para proceder à descrição, ele fala de cada departamento da fábrica. Primeiramente descreve o escritório, no SegT 1. Após concluir o SegT 1, o informante inicia o SegT 2, que seria dedicado a descrever outro departamento da fábrica, a serraria. Todavia, antes de desenvolver propriamente o SegT 2, o informante logo o interrompe e inicia o SegT 3, a fim de descrever outro departamento, em que se risca o papelão. Ao encerrar o SegT 3, o informante desenvolve o SegT 4, dedicado à descrição de mais um departamento, onde fica a impressora. Nesse exemplo, a interrupção do SegT 2 (que não volta a ser desenvolvido no restante do texto) representa um caso de descontinuidade por ruptura tópica ${ }^{6}$.

O exemplo em (4) mostra um caso de descontinuidade por inserção tópica, identificado em uma descrição:

\section{(4) [SegT mínimo 1]}

então é um lugar muito bonito... é... era né? no caso... e que eu tenho saudade... eu tenho muita saudades de lá... de de de toda essa coisa... éh bonita né?

\section{[SegT mínimo 2]}

tinha uns quadros muito grande os quadros da... da Via Sacra... eram grandes... bem grandes mesmo um... devia sê(r) um e meio ou dois metros... a pintura sabe?... éh o trabalhado da pintura... da... da... da moldura do dos quadros também... era muito bem feita muito trabalhada assim uma coisa uma Obra de ARte mesmo ela era Uma Obra de arte...

\section{[SegT mínimo 1]}

éh foi uma pena tê(r)... né?... por algum motivo ou o(u)tro tê(r) sido demolida... mas... era um lugar que eu gosto... gosTAva MUIto... de í(r) e de:: de tá... fazen(d)o as minhas meditações Doc.:O.K. (Banco de Dados IBORUNA: AC-102; DE: L. 45-53).

No texto em que se encontra esse exemplo, a informante descreve uma determinada igreja. No trecho aqui transcrito, a informante inicia um tópico (SegT 1) em que focaliza sua saudade e seu apreço por essa igreja, interrompe esse tópico e desenvolve, de modo completo, outro tópico (SegT 2), sobre os quadros da Via Sacra da igreja, e, depois disso, retoma e termina o tópico anterior (SegT 1). Assim, o desenvolvimento do SegT 2 no interior do SegT 1 representa um caso de descontinuidade por inserção tópica.

O exemplo em (5), parte de uma das descrições analisadas em nosso trabalho, ilustra a descontinuidade por alternância tópica:

\section{(5) [SegT mínimo 1]}

aí entra assim... a sala é gosto::sa é bem grande a sala da minha vó (...) na sala tem um/ uma:: mesa grande de made(i)ra [onde a gente] [Doc.: ah tá] janta... tem uns dois sofá:: uma mesinha de centro né? (...)

[SegT mínimo 2]

aí:: éh:: aí tem a cozinha... ah a cozinha da minha vó é muito gostosa tam(b)ém... (...) tem uma gelade(i)ra a cozinha da minha vó não é tão espaçosa... tem uma gelade(i)ra... uma outra me::sa a pia o fogão... (...)

\section{[SegT mínimo 1]}

ah e na sala tam(b)ém tem uma saCAda... hum:: legal [Doc.: sacada] uma sacadinha assim... que dá pa trás do prédio... [Doc.: uhum ((concordando $)$ que dá pa trás assim porque atrás do prédio é o estacionamen::to... então tem flores lá tam(b)ém então essa sacada dá pa trás...

\section{[SegT mínimo 2]}

e na cozinha tam(b)ém tem uma janela uma janela... uma janela pequena assim que dá pra rua... a:: a cozinha dá pra rua... é(Banco de Dados IBORUNA: AC-022; DE: L. 301-322).

${ }^{6} \mathrm{O}$ trecho classificado como SegT mínimo 2, embora não seja desenvolvido, pode ser considerado como um SegT mínimo, por conta de sua relevância dentro da estrutura tópica do texto, já que esse trecho introduz mais um dos departamentos da fábrica (a serraria) em um texto estruturado justamente na descrição de cada departamento da fábrica. 
No texto de onde esse exemplo é retirado, a informante descreve o apartamento de sua avó. Como se pode notar, no trecho do exemplo, ela focaliza alternadamente dois tópicos, a sala (no SegT 1) e a cozinha (no SegT 2), o que constitui um caso exemplar de descontinuidade por alternância tópica.

O último tipo de caso encontrado em nosso corpus refere-se à descontinuidade por expansão tópica, que pode ser vista no exemplo em (6), extraído agora de uma narrativa de experiência:

\section{(6) [SegT mínimo 1]}

... éh:: foi interessante... porque:: lá eu aprendi muito com a política... foram seis meses... que eu passei:.... atrás de votos... visitan::do pessoas... éh:: no sítio... éh na cidade de casa em casa encontrando os amigos falando sobre política... éh.: tivemos:: comícios... éh:: enfim... foi uma:: foi gratificante... (...) tive essa aventura... que..... achei muito bom...

\section{[SegT mínimo 2]}

então durante eram (inint.) a gente tava sempre acompanhado foram seis meses acompanhando amigos visitando aqui visitando ali... (...)

[SegT mínimo 3]

tivemos... como candidato a vice... um ex-farmacêutico de Ipiguá... (...)

\section{[SegT mínimo 4]}

Doc.: o senhor ficô(u) decepcionado? Inf.: não eu de forma alguma porque o que eu queria levá(r) pra Ipiguá... era um::/ uma coisa nova Ipiguá tava começando... seria uma coisa nova..... não consegui... mas não fiquei decepcionado porque segui minha vida... (...) e:: então de forma alguma eu fiquei decepcionado

\section{[SegT mínimo 5]}

Doc.: e o que que o senhor aprendeu? Inf.: aprendi a conhecê(r) as pessoas porque muitas pessoas... éh.: às vezes pessoas que você espera... éh:: que são teus amigos... (...) (Banco de Dados IBORUNA: AC-113; NE: L. 7-50).

Nesse caso, no SegT 1, o informante focaliza sua experiência de candidatar-se a prefeito de sua cidade, e menciona, de passagem, que sua candidatura teria lhe proporcionado um grande aprendizado. Depois de finalizar esse SegT, o informante desenvolve os SegTs 2, 3 e 4 e, então, no SegT 5, centra-se, exatamente, na lição aprendida na candidatura. O SegT 57 é, portanto, uma expansão de dados colocados de passagem no SegT 1, configurando um caso de descontinuidade por expansão tópica.

Como se pode notar a partir dos exemplos acima, bem como dos dados da tabela 1, narrativas de experiência e descrições apresentam uma boa diversidade de formas de linearização dentre as formas distinguidas por Jubran. Das oito formas reconhecidas pela autora, cinco foram encontradas considerando os dois gêneros: em narrativas, foram encontradas quatro formas continuidade, descontinuidade por ruptura, descontinuidade por inserção e descontinuidade por expansão (como se vê na segunda coluna da tabela 1) - e, em descrições, foram encontradas cinco formas - essas mesmas quatro encontradas em narrativas mais a descontinuidade por alternância (conforme mostra a terceira coluna da tabela 1).

Essa constatação constitui, a nosso ver, uma indicação considerável de que as formas de linearização tópica distinguidas por Jubran (2006) não seriam formas típicas apenas do gênero inicialmente analisado pela autora, mas seriam formas relevantes também no funcionamento e na análise de outros gêneros. Os dois gêneros considerados aqui não foram selecionados por termos identificado,

\footnotetext{
${ }^{7}$ Conforme mostra o exemplo, o SegT 5 é introduzido pelo documentador, não propriamente pelo informante. No entanto, convém aqui esclarecer que, para nós, esse tipo de fato em nada compromete a identificação do processo de descontinuidade por expansão tópica (nem qualquer das análises feitas neste artigo). A nosso ver, embora os textos do nosso corpus sejam centrados no informante, e não no documentador, tais textos resultam da atuação colaborativa de ambos (informante e documentador), os dois participando, de modo integrado, da construção do texto, sendo ambos corresponsáveis pelo gerenciamento da Organização Tópica e de outros processos de construção textual.
} 
previamente, qualquer tipo de relação com as formas de linearização tópica da autora, sendo escolhidos de modo aleatório no que se refere à relação com esses processos de linearização - a seleção do corpus, como explicado acima, decorreu de outros fatores. Dado, então, esse caráter aleatório da seleção dos gêneros aqui em análise, é pertinente pensar que as formas de linearização tópica de Jubran (2006) provavelmente devem ser categorias propensas a ocorrer na língua em geral, em diferentes tipos de gêneros textuais.

Nos gêneros aqui analisados, não foram encontradas ocorrências dos três últimos tipos de linearização distinguidos por Jubran (2006) - transição tópica, sobreposição tópica e movimento tópico. Mesmo assim, entendemos que esses três mecanismos podem integrar uma tipologia geral. Tais mecanismos parecem ser vistos, pela própria autora, como muito específicos e pouco frequentes até mesmo no gênero por ela analisado (conversação espontânea). Desse modo, a ausência desses mecanismos em narrativas e em descrições não indicaria, necessariamente, que eles seriam particularidades do gênero estudado por Jubran, podendo essa ausência decorrer da própria natureza desses mecanismos, que seriam, de fato, pouco propensos a ocorrer em qualquer gênero. Além disso, considerando que o corpus aqui utilizado é relativamente pouco extenso e que, apesar disso, foi verificada a maior parte das categorias da tipologia, acreditamos que uma análise de narrativas e de descrições em um corpus um pouco mais extenso, ou mesmo de algum outro gênero, muito provavelmente levaria à identificação de casos de transição, superposição e movimento de tópicos. Assim, nossa visão é a de que todas as categorias propostas pela autora, de fato, são relevantes e devem constar numa tipologia geral de formas de linearização tópica.

Além de indicar que as categorias da tipologia de Jubran (2006) são necessárias, os exemplos explicados acima e os resultados expostos na tabela 1 permitem concluir, de modo complementar, que essas categorias parecem também ser suficientes. A segunda e a terceira colunas da tabela reúnem todas as diferentes formas de linearização encontradas nas narrativas e nas descrições analisadas, e, como se pode ver na tabela, todas essas formas encontradas encaixam-se entre as formas da tipologia, o que é também ilustrado pelos exemplos acima. Ou seja, a análise de narrativas e descrições não chegou a revelar formas novas de linearização, diferentes daquelas já previstas na tipologia da autora. Assim, pode-se ver que essa tipologia prevê uma diversidade de formas de linearização tópica suficientemente abrangente para descrição dos gêneros textuais aqui em pauta, diferentes do inicialmente analisado por Jubran.

Embora, como acabamos de dizer, a tipologia tenha se mostrado suficiente, nossos dados apontaram para a pertinência e para a relevância da inclusão de algumas especificações de suas categorias e de seu modo de funcionamento, para permitir uma análise tópica mais detalhada e precisa. É por isso que, neste artigo, estamos considerando que a tipologia em apreço é adequada em linhas gerais, ou seja, é adequada, porque suas categorias são, de fato, necessárias e suficientes, e é adequada em linhas gerais, porque suas categorias carecem de algumas especificações para uma descrição mais detalhada do processo de sequenciamento tópico - embora estejamos propondo algumas especificações, ainda entendemos que as categorias já sugeridas sejam suficientes (e que a tipologia seja adequada), pois as especificações propostas não envolvem a proposição de categorias novas, mas são especificações das categorias já existentes.

No restante desta seção, discutimos, então, algumas especificações que se mostraram significativas em nossa análise. A esse respeito, nossa sugestão é que a tipologia incorpore três especificações: (i) a subdivisão da categoria de continuidade tópica em continuidade tópica com transição pontual e com transição gradual; (ii) a subdivisão da categoria de descontinuidade tópica por ruptura em descontinuidade por ruptura de SegT desenvolvido e descontinuidade por ruptura de SegT não desenvolvido; (iii) o reconhecimento da possibilidade de ocorrência simultânea de duas formas diferentes de linearização tópica.

A primeira especificação que nos parece interessante, então, refere-se à subdivisão da categoria de continuidade tópica em continuidade tópica com transição pontual e continuidade tópica com transição gradual. O primeiro subtipo verifica-se quando há um ponto exato de passagem de um SegT mínimo a outro, isto é, um ponto claro, evidente, de transição entre um SegT e outro. Isso se verifica no exemplo em (2), discutido acima, e também no exemplo seguinte em (7), extraído de um texto do gênero descrição, em que o primeiro SegT aborda o tópico discursivo "Cozinha", havendo um ponto claro de mudança para o tópico "Parte de fora da casa”, abordado no SegT 2: 
tem... aí depois saindo do corredor tem a cozinha... a cozinha é bem grande com uma mesa de made(i)ra bem... grande mesmo aquelas mesa de área mesmo... lá geralmente eu guardo a minha moto fica tudo abarrotado todo dia... (...) tem a pi::a o fogão do lado da pi:.:.... a gelade::(i)ra... é bem grande também... um armário de cozinha... nesse armário fica o telefone na parte de ba(i)xo... onde guarda (as coisa talheres essas coisas)...

[SegT mínimo 2]

e.: tem a parte de fora da casa... onde é os domínios da Diana minha cachorra... [Doc.: uhm] ((risos)) então no fundo da minha casa tem o(u)tro terreno... lá a gente tem uma hor::ta pequenininha tem um pé de caju um pé de goiaba... tem um monte de coisa um monte plantinha... (...) (Banco de Dados IBORUNA: AC-050; DE: L. 249-261).

A transição pontual pode ser evidenciada por meio de diferentes mecanismos. Embora nossa pesquisa não tenha focalizado o levantamento dos mecanismos utilizados para promover essa transição, duas estratégias se destacaram em nossa análise: a introdução "abrupta", istoé, pontual, repentina, de um novo referente que passa a ser focal a partir de sua introdução no texto, dando início a um novo SegT; e/ou a marcação da mudança de SegT por meio de um Marcador Discursivo. O exemplo em (7) ilustra uma transição em que ocorrem esses dois mecanismos. A sequência de SegTs nesse exemplo é extraída de uma descrição em que o informante descreve sua casa. O SegT 1 aborda a cozinha. Durante todo esse SegT 1, não é feita nenhuma menção à parte de fora da casa. No início do SegT 2, ocorre a interrupção completa da abordagem do tópico "Cozinha" e a introdução abrupta, repentina, do referente "parte de fora da casa", que é, então, colocado em foco, tornando-se tópico discursivo e dando origem a um novo SegT mínimo. Além dessa mudança evidente de foco referencial, há o uso do Marcador Discursivo "e" no início do SegT 2, que explicita a mudança de tópico, marcando, no caso, a relação de adição de novo tópico.

A transição em (7), desse modo, representa um caso de continuidade tópica em que se pode identificar um ponto exato de transição entre SegTs mínimos, ilustrando o que estamos considerando como continuidade tópica com transição pontual. Essa situação ocorreu na grande maioria dos casos de continuidade tópica que analisamos. No entanto, observamos uma recorrência considerável de casos em que parece não haver um ponto tão claro de passagem de um SegT a outro. Nesses casos, entre dois SegTs adjacentes, há um conjunto de enunciados que teriam um estatuto tópico ambíguo, isto é, haveria certa ambiguidade em relação ao lugar desse conjunto de enunciados na organização tópica do texto, no sentido de que esse conjunto poderia ser interpretado como pertencendo ao SegT anterior (promovendo a finalização desse SegT), mas poderia também ser interpretado como pertencendo ao SegT seguinte (promovendo a introdução desse novo SegT). Essa situação pode ser observada na transição de SegTs abaixo, extraída de uma narrativa de experiência:

\section{(8) [SegT mínimo 1]}

aí logo que eu me casei daí um mês ou dois... eu fiquei grávida... do meu filho mais velho... aí fiz trata/ fui fazê(r) pré-natal:: tudo né? no logo no comecinho... aí eu já tive logo no começo problema de querê(r) abortá(r)... aí eu tive que fazê(r) muito repou::so... tomei muito reMÉ::dio... aí:: a/ nos nove me::ses aí nasceu o H.... que é o meu filho mais velho... né? (...) chorava MUIto por/ ((risos)) ele era chorão ((fala rindo))... ele num gostava de ficá(r)... no berço né? as enfermeiras... éh:.... iam no quarto e falavam - "eu num sei que que eu faço com aquele filho seu porque ele só chora" -... ele só ficava no colo... de pequenininho... éh a/ às vezes à noite tava com so::no... o o V. tinha que carregá(r) ficá(r)... de noite com ele com cobertor porque tava frio fazia é/ época de frio né?... com ele no colo aTÉ ele pegá(r) uma idade

aí a gente ficô(u) até com medo de:: de tề (r) o(u)tro né?... aí a minha mãe atéfalô(u) assim - "nossa eu pensei que você era igual eu... mas pelo menos eu tô vendo que você num é" -

\section{[SegT mínimo 2]}

aí daí quatro anos a gente levô(u) mais ou menos né?... aí uns três anos e po(u)co eu fiquei grávida... do E.... que é o meu filho do meio... aí já foi uma gravidez MAIS ou menos normal... mas aí a gente ficô(u) muito feliz:.... porque né?... pa quem num criava tê(r) o segundo... ((risos)) já era muita sorte... aí na gravidez do E. o E. já era eu já percebia na gravidez que ele já era mais... já na na própria gravidez eu percebi que era mais (tímido)... (...) (Banco de Dados IBORUNA: AC-102; NE: L. 13-34). 
Em (8), o SegT mínimo 1 aborda a gravidez que a informante teve de seu primeiro filho (filho mais velho) e a fase inicial da vida desse filho. No segmento textual separado como SegT 2, a informante já aborda a gravidez de seu segundo filho (filho do meio). Entre esses dois SegTs, há um trecho (destacado em itálico) que, a nosso ver, pode ser interpretado como parte do SegT 1 ou como parte do SegT 2.

Por um lado, o trecho em destaque poderia ser visto como uma finalização do SegT 1. Nesse caso, esse trecho apresentaria uma consequência dos problemas enfrentados pela informante durante a gravidez de seu primeiro filho e durante algum tempo após o nascimento, e um relato da avaliação final feita pela mãe da informante. Por outro lado, também parece pertinente já reconhecer o trecho em destaque como pertencente ao SegT 2, como uma introdução à discussão apresentada nesse novo SegT. Nesse caso, esse trecho veicularia uma ressalva ao que é discutido no SegT 2 (a de que a informante tenha ficado grávida uma segunda vez, embora tenha ficado com medo de ter outro filho), assim como uma preparação para essa discussão (o reconhecimento da mãe da informante quanto à possibilidade de gravidez da filha, possibilidade, de fato, confirmada na sequência do texto, no desenrolar do SegT 2, com o relato da nova gravidez).

Essa dupla possibilidade de encaixamento do trecho em destaque (tanto no final do SegT 1, quanto no início do SegT 2) se deve, em certa medida, ao fato de o trecho veicular referências mais genéricas, que não dizem respeito especificamente nem ao primeiro, nem ao segundo filho. As referências aí giram em torno do medo do casal de ter outros filhos e da avaliação da mãe da informante. Ou seja, são referências que abrangem tanto as referências anteriores, mais específicas ao primeiro filho, quanto as referências posteriores, mais específicas ao segundo filho.

Pode-se notar que, até o final do trecho separado como SegT 1, há referências que se dirigem diretamente ao filho mais velho. A partir daí, onde começa o trecho intermediário, cessam as referências ao filho mais velho. Porém, nesse trecho intermediário, ainda não há referências específicas ao segundo filho. Somente mais adiante, no início do trecho destacado como SegT 2, é que começam as referências diretas ao segundo filho. A presença dessas referências genéricas situadas entre dois encadeamentos diferentes de referências específicas é um dos principais fatores que parecem justificar a dupla possibilidade de interpretação aqui levantada.

Enfim, a situação descrita no exemplo em (8) ilustra o que consideramos como o caso de continuidade tópica com transição gradual entre SegTs mínimos ${ }^{8}$. Trata-se de uma transição em que não há um ponto evidente, inequívoco, de mudança tópica. O que se vê entre dois SegTs, na verdade, seria um trecho textual transitório. Essa diferença entre uma transição pontual e uma transição gradual fica bastante nítida comparando, por exemplo, os sequenciamentos dos exemplos em (7) e (8).

Em nossa pesquisa, identificamos uma frequência majoritária da transição pontual em relação à transição gradual. Dos 119 casos de continuidade tópica identificados, 91,6\% (109 ocorrências) constituem transição pontual, enquanto 8,4\% (10 ocorrências) consistem em transição gradual. Apesar dessa predominância de um dos tipos de transição, a diferença entre os dois tipos existe e, a nosso ver, cabe ser considerada. A noção de continuidade tópica envolve a passagem entre o término de um SegT mínimo e o início de outro. Ou seja, a noção envolve o trabalho (tanto dos interlocutores, quanto do analista do texto) de identificar um ponto de passagem entre os SegTs. A distinção aqui proposta entre continuidade pontual e gradual diz respeito justamente ao "problema" da identificação desse ponto. Trata-se de duas alternativas possíveis, tendo em vista onde e/ou como se dá a passagem entre SegTs. Pode-se dizer que se trata de formas diferentes de linearização tópica, que pressupõem procedimentos diferentes de construção e interpretação de texto. Em outras palavras, pode-se dizer que são formas diferentes de elaboração e negociação da Organização Tópica do texto.

Convém aqui observar que, para a identificação da diferença entre transição pontual e gradual (assim como para a identificação de todas as outras formas de linearização consideradas neste artigo), levamos em conta elementos estritamente linguísticos - seguindo

\footnotetext{
${ }^{8}$ Convém esclarecer que a continuidade tópica com transição gradual, aqui proposta, não se confunde com a categoria da transição tópica, já reconhecida na tipologia de Jubran (2006). A transição tópica da tipologia de Jubran diz respeito a um trecho textual que, em si, chega a constituir um SegT mínimo (por apresentar propriedades suficientes para adquirir esse estatuto), tratando-se, assim, de um SegT mínimo (inteiro) de transição. Na categoria aqui proposta, os trechos de transição não constituem (eles próprios) SegTs mínimos, sendo, na verdade, apenas conjuntos de enunciados que são partes de SegTs mínimos.
} 
a própria metodologia usada na tipologia de Jubran (2006) e na GTI de modo geral. Especificamente, avaliamos o próprio conteúdo temático (ou melhor, o conteúdo tópico) constitutivo dos SegTs e, eventualmente, recorremos também a outros elementos linguísticos, como os Marcadores Discursivos.

Olhando para além do material linguístico, é importante reconhecer que elementos extralinguísticos como gestos e olhares dos interlocutores também podem influenciar os processos de linearização tópica (e muitos outros processos linguístico-textuais), podendo vir a definir, em certa medida, onde seria a transição pontual entre dois SegTs ou até mesmo se uma transição seria pontual ou, na verdade, gradual. No entanto, neste artigo, delimitamos nossa análise aos elementos linguísticos, para manter a metodologia da GTI e também porque a análise de fatos extralinguísticos demandaria um corpus constituído, dentre outros recursos, de interações filmadas, o que não é o caso do material que analisamos (que contém interações verbais apenas com gravações de áudio e respectivas transcrições).

Apesar da influência de fatores extralinguísticos, acreditamos que a delimitação aqui estabelecida não compromete as análises feitas. A consideração de elementos extralinguísticos poderia precisar ou até alterar a análise de certos exemplos particulares, porém certamente ainda permaneceria válida a tipologia de formas de linearização tópica em discussão, inclusive as subcategorias aqui propostas, como a distinção entre transição pontual e gradual. Desse modo, no presente trabalho, optamos pela delimitação à análise de elementos linguísticos, reconhecendo o estudo de fatores extralinguísticos como um tema relevante de pesquisa e um possível caminho para continuação deste trabalho.

Passamos agora para a segunda especificação que parece pertinente incorporar na tipologia de Jubran (2006), a qual envolve a categoria da descontinuidade por ruptura tópica. A autora identifica o processo de ruptura tópica como a ruptura de um SegT mínimo não desenvolvido, ou seja, um SegT mínimo é iniciado, mas não chega a se desenvolver propriamente, porque o interlocutor muda logo o foco do seu discurso, passando, então, a desenvolver outro SegT, e o tópico do SegT interrompido não volta a aparecer no texto. O exemplo em (3) explicado acima ilustra um caso de ruptura que corresponde exatamente ao que é definido como ruptura tópica por Jubran (2006). Nesse exemplo, o SegT 2 (que abordaria um setor da empresa descrita - a serraria), embora iniciado, não chega a ser desenvolvido propriamente, sendo antes interrompido para desenvolvimento de um SegT subsequente.

Além do processo de ruptura tópica nos moldes descritos por Jubran (2006), identificamos em nossos dados um tipo de ruptura um pouco diferente. O exemplo em (9), identificado em uma das descrições de nosso corpus, ilustra esse tipo particular de ruptura:

\section{(9) [SegT mínimo 1]}

éh depois tinha o o/ ela tinha o Santíssimo aonde ficava... o o:: o Santíssimo... era:: um lugar que tinha assim tipo d'uma:.... d'uma gra::de ((ruído))... que fechava porque antigamente... éh num ficava exposto aberto pra gente entrá(r) e saí(r) a hora que queria... né:.: eles ficava fechado... com umas cortinas vermelhas... sabe?... tudo assim MUITO bonito era... era... ao mesmo tempo que era... ruim por sê(r)... éh proibido po/ pro... pro leigo num tinha tanto acesso... a chegá(r) tão perto do Santíssimo... mas era uma coisa bonita porque tinha era tudo muito bem fei::to... éh muito trabalha::do... no mármore trabalhado... o Santíssimo com flores com velas aqueles an::jos... coloridos né? seguran(d)o aqueles castiçais... com ve.:la... cortinas verme.:Ihas... era um lugar que tudo isso/ de/

\section{[SegT mínimo 2]}

mesmo quando eu era pequena eu gostava porque às vez eu ia c’a minha mãe... e criança deita no chão fica olhando o teto TOdo pinTA::do em douRA::.do aquelas flores dourado com ver::de... as iMAgens dos SANtos... éh pinTAdo no TEto (...) (Banco de Dados IBORUNA: AC-102; DE: L. 232-244).

O exemplo em (9) é extraído de um texto em que a informante descreve uma determinada igreja. No SegT 1, ela descreve suas recordações sobre o local onde ficava o Santíssimo. Após um considerável desenvolvimento do SegT 1, este é claramente interrompido. Observe-se que, no final do SegT 1 , a informante inicia um enunciado para acrescentar alguma característica do local onde ficava o Santíssimo, mas não chega a completá-lo ("era um lugar que tudo isso/ de/"). O enunciado é interrompido pela 
introdução do SegT mínimo 2, em que a informante passa a centrar-se na descrição do teto da igreja, não retornando, no restante do texto, ao tópico do SegT 1.

Note-se que o processo de ruptura tópica identificado por Jubran (2006) difere do processo ilustrado em (3). No exemplo em (3), que ilustra a ruptura tópica tal como identificada pela autora, o SegT mínimo interrompido não chega propriamente a se desenvolver, ou seja, o falante introduz o que, de fato, chega a ter estatuto de tópico, mas não desenvolve esse tópico. De maneira diferente, no exemplo em (9), o SegT interrompido é, como já dito, consideravelmente desenvolvido antes de sofrer a ruptura para a introdução do SegT seguinte?

Desse modo, propomos uma divisão da categoria de ruptura tópica em duas subcategorias: (i) ruptura de SegT mínimo não desenvolvido, tipo já proposto por Jubran (2006); e (ii) ruptura de SegT mínimo desenvolvido, tipo aqui sugerido. Em nossos dados, encontramos sete ocorrências de ruptura tópica, sendo uma ocorrência do primeiro tipo e seis ocorrências do segundo tipo (isto é, o tipo aqui proposto ocorreu até com mais frequência que o tipo já identificado por Jubran). A nosso ver, a subdivisão aqui proposta é pertinente na medida em que, de fato, separa duas formas alternativas de ruptura. Essa modalidade de descontinuidade tópica envolve, entre outros aspectos, o abandono de um tópico para introdução de outro, sem retorno ao tópico abandonado. Nos dois subtipos aqui distinguidos, ocorre o abandono de um tópico e a ausência de retorno a ele, isto é, em ambos os casos, os interlocutores não têm acesso ao sentido de fechamento do tema abordado, à conclusão do tópico; o sentido é de algo em aberto. Porém, na ruptura de SegT não desenvolvido, o sentido de incompletude tópica é muito maior, já que o tópico é pouco ou nada abordado, enquanto, na ruptura de SegT desenvolvido, falta apenas o sentido de finalização de abordagem tópica, já que o tópico foi desenvolvido. Ou seja, também aqui a distinção diz respeito a diferentes formas pelas quais os interlocutores se relacionam com a condução da Organização Tópica do texto.

Finalmente, a terceira especificação que propomos para a tipologia de Jubran (2006) diz respeito ao reconhecimento da possibilidade de ocorrência simultânea de estratégias de linearização tópica. A tipologia da autora parece pressupor que, na transição de um SegT mínimo para outro, verifica-se sempre um único tipo de estratégia. No entanto, em nosso corpus, pudemos observar a possibilidade de ocorrência simultânea de duas estratégias, isto é, a introdução de um SegT no decorrer de um texto pode representar, ao mesmo tempo, dois tipos de transição.

A esse respeito, observamos dois tipos de simultaneidade de estratégias, ambos envolvendo a categoria da expansão tópica. Um tipo se refere ao fato de que o processo de expansão tópica, que é um processo de descontinuidade, pode representar também um processo de continuidade. Ou seja, por um lado, há descontinuidade entre o SegT desenvolvido por expansão e a primeira menção a seu tópico em algum SegT anterior e, por outro lado, há continuidade entre esse SegT expandido e o SegT imediatamente anterior a ele. Isso pode ser notado no exemplo em (6) acima, retirado de uma narrativa de experiência, retomado abaixo em (10):

\section{(10) [SegT mínimo 1]}

... éh:: foi interessante... porque:: lá eu aprendi muito com a política... foram seis meses... que eu passei:.... atrás de votos... visitan::do pessoas... éh:: no sítio... éh na cidade de casa em casa encontrando os amigos falando sobre política... éh:: tivemos:: comícios... éh:: enfim... foi uma:: foi gratificante... (...) tive essa aventura... que:.... achei muito bom...

\section{[SegT mínimo 2]}

então durante eram (inint.) a gente tava sempre acompanhado foram seis meses acompanhando amigos visitando aqui visitando ali... (...)

[SegT mínimo 3]

tivemos... como candidato a vice... um ex-farmacêutico de Ipiguá... (...)

\section{[SegT mínimo 4]}

\footnotetext{
${ }^{9} \mathrm{Na}$ descrição em que se encontram os SegTs mínimos em (9), pode-se notar, inclusive, que o SegT 1 é um dos SegTs mais desenvolvidos do texto, em termos de extensão, se comparado com os demais SegTs do texto.
} 
Doc.: o senhor ficô(u) decepcionado? Inf.: não eu de forma alguma porque o que eu queria levá(r) pra Ipiguá... era um::/ uma coisa nova Ipiguá tava começando... seria uma coisa nova:.... não consegui... mas não fiquei decepcionado porque segui minha vida... (...) e:: então de forma alguma eu fiquei decepcionado

\section{[SegT mínimo 5]}

Doc.: e o que que o senhor aprendeu? Inf.: aprendi a conhecê(r) as pessoas porque muitas pessoas... éh:: às vezes pessoas que você espera... éh:: que são teus amigos... (...) (Banco de Dados IBORUNA: AC-113; NE: L. 7-50).

Nesse exemplo, conforme explicado acima, a introdução do SegT 5 representa um caso de descontinuidade por expansão tópica, já que esse SegT desenvolve dados anunciados, de passagem, no SegT 1. Por outro lado, a introdução do SegT 5 configura simultaneamente um processo de continuidade tópica. Observe-se que o SegT 4 trata da maneira pela qual o informante lidou com o resultado das eleições, narrando como se sentiu após saber que não havia conseguido se eleger. Após desenvolver e concluir esse SegT 4, o informante dá início ao SegT 5, para tratar, então, da lição tirada da candidatura. Desse modo, entre o SegT 4 e o SegT 5 , há um processo de continuidade tópica, dado que o SegT 5 só é iniciado após o encerramento do SegT imediatamente anterior.

Considerando, então, que, entre o SegT 1 e o SegT 5 ocorre descontinuidade, e que, entre o SegT 4 e o SegT 5, ocorre continuidade tópica, consideramos que, nesse tipo de situação, o processo de expansão tópica envolve, simultaneamente, um processo de descontinuidade e um processo de continuidade tópica. Ou seja, o tópico expandido pode envolver dois processos diferentes simultaneamente: um processo de descontinuidade, conforme identificado por Jubran (2006), e um processo de continuidade, conforme pudemos identificar a partir da análise de nossos dados.

Além dessa situação, identificamos outro tipo de simultaneidade, também envolvendo a expansão tópica. Esse outro tipo se verifica quando o SegT expandido é inserido no interior de outro SegT. Ocorre aí, portanto, a simultaneidade de dois processos de descontinuidade: expansão e inserção. Isso pode ser notado no exemplo em (11) abaixo, que é parte de uma das descrições constituintes do nosso corpus:

(11) [SegT mínimo 1]

Inf.: posso... então você conhece ali Fronte(i)ra né?... (...) então entrando ali... a/ tem bastante condomínios né?... e o nosso ahm:: rancho é no condomínio:: Lago e Sol... então a gente tem lá um rancho bom:.... né?... um rancho gran::de... ele tem quatro quar::tos... ele tem três banhe::(i)ro né?... tem uma lavanderia gran::de... uma área da frente bem gran::de... tem uma frente boni::ta... e na fre/ nosso rancho fica BEM assim pertinho da água... (...)

[SegT mínimo 2]

mas é muito gosto::so... você vai lá você passa um feria::do... você leva a famí::lia você leva os í(r)/ conheci::do... os cole::.ga... (...)

[SegT mínimo 3]

fim de ano quando chega... no.:... na fase do Ano Novo... a gente costuma í(r) né?... quase tudo:: a família no ran::cho... teve:: fim de ano... nos já até jantamo(s) em cinqüenta pessoa Doc.: nesse rancho?

Inf:: nesse rancho

\section{[SegT 4]}

Doc.: então os quartos são bem grandes? Inf.: é é beliche... cada quarto... tem... duas beliche de casal e duas de solte(i)ro... uma em cima o(u)tra em ba(i)xo... de alvenaria [Doc.: ah de alvenaria?] de alvenaria (...)

\section{[SegT mínimo 3]}

então e a gente passa lá Ano No::vo... Carnaval:.... eles levam aqueles ca/ som:.... ah no Ano Novo é muito lindo... tem queima de fo:gos (...) (Banco de Dados IBORUNA: AC-132; DE: L. 209-244). 
Em (11), no SegT 1, a informante faz uma descrição geral do rancho da família, mencionando, de passagem, os quartos do rancho. Posteriormente, os dados mencionados no SegT 1 a respeito dos quartos são expandidos e desenvolvidos na forma de um SegT mínimo, no caso, o SegT 4. Nesse SegT 4, a informante centra seu texto especificamente nas características dos quartos do rancho. Considerando, então, que o SegT 4 é desenvolvido a partir de dados anunciados de passagem anteriormente no SegT 1, observa-se que, do SegT 1 para o SegT 4, ocorre um processo de descontinuidade por expansão tópica.

Ao mesmo tempo, o exemplo em (11) apresenta um caso de inserção tópica envolvendo o tópico expandido. No SegT 3, a informante começa a discorrer sobre os fins de ano que a família costuma passar no rancho. Entretanto, a informante interrompe o SegT 3 e desenvolve o SegT 4. Após a finalização do SegT 4, o SegT 3, então, é retomado e concluído. Assim, a introdução do SegT 4 no decorrer da descrição em (11), especificamente no interior do SegT 3, representa um caso de inserção tópica.

Desse modo, tendo em vista que o SegT 4 está envolvido, concomitantemente, em um processo de expansão e em um processo de inserção tópica, entendemos que, na linearidade discursiva, a transição entre tópicos discursivos pode envolver, simultaneamente, dois processos de descontinuidade.

Em síntese, casos como os exemplificados em (10) e (11) mostram a possibilidade de coocorrência de duas formas de transição tópica na introdução de um mesmo SegT mínimo na linearidade textual, particularmente a coocorrência de expansão tópica e continuidade tópica, bem como a coocorrência de expansão tópica e inserção tópica. A nosso ver, essa constatação representa uma característica interessante do funcionamento das categorias da tipologia de Jubran (2006), na medida em que evidencia a dinamicidade e a complexidade da condução do processo de Organização Tópica pelos interlocutores.

\section{CONCLUSÃO}

Neste artigo, avaliamos a tipologia de formas de linearização tópica proposta por Jubran (2006). Os dados analisados indicam que a diversidade de categorias da tipologia é relevante e suficientemente ampla para descrever a linearização tópica nos gêneros aqui analisados, indicando, ao mesmo tempo, a pertinência da inclusão de algumas especificações nessas categorias, conforme propusemos. Nesse sentido, pode-se dizer que nosso trabalho corrobora, em linhas gerais, a tipologia de Jubran, propondo algumas complementações.

Reconhecemos que nossa investigação lidou apenas com dois gêneros e que, naturalmente, uma pesquisa mais completa deveria estender a análise para uma diversidade maior de gêneros - o que, a propósito, constitui um dos passos seguintes do nosso trabalho (PENHAVEL, 2013). De todo modo, entendemos que os gêneros aqui estudados em conjunto com o contemplado no trabalho de Jubran (2006) compõem uma variedade de gêneros suficiente para se pensar (pelo menos como uma forte hipótese) que a tipologia da autora (incluindo as complementações aqui propostas) seria uma classificação possivelmente válida para a língua em geral, não apenas para determinados gêneros.

Nesse sentido, esperamos que este trabalho possa representar uma contribuição significativa para a atual fase de aprimoramento e consolidação da GTI, um quadro teórico-metodológico relativamente novo, essencialmente brasileiro, que vem se mostrando altamente produtivo na descrição e na explicação de fenômenos textuais de diversos tipos. Esperamos, enfim, que esta pesquisa possa incentivar a produção de outras que almejem avaliar a eficácia da GTI, corroborando princípios, identificando problemas e propondo complementações e reformulações para o modelo. 


\section{REFERÊNCIAS}

CASTILHO, A. T. O português culto falado no Brasil - história do Projeto Nurc no Brasil. In: PRETI, D. URBANO, H. (Org.). A linguagem falada culta na cidade de São Paulo. v. IV, Estudos. São Paulo: T.A.Queiroz/Fapesp, 1990. p.141-197.

GONÇALVES, S. C. L. Projeto ALIP (Amostra Linguística do Interior Paulista): O português falado na região de São José do Rio Preto - constituição de um banco de dados anotado para o seu estudo. São José do Rio Preto: UNESP, 2007. Disponível em: $<$ http://www.iboruna.ibilce.unesp.br>.

JUBRAN, C. C. A. S. Tópico Discursivo. In JUBRAN, C. C. A. S.; KOCH, I. G. V. (Org.). Gramática do português culto falado no Brasil - v.I: Construção do texto falado. Campinas: Editora da UNICAMP, 2006. p. 89-132.

Uma gramática textual de orientação interacional. In: CASTILHO, A. T. et al. (Org.). Descrição, história e aquisição do português brasileiro. Campinas; São Paulo: Pontes; FAPESP, 2007. p. 313-327.

JUBRAN, C. C. A. S.; KOCH, I. G. V. (Org.). Gramática do português culto falado no Brasil - v. I: Construção do texto falado. Campinas: Editora da UNICAMP, 2006.

JUBRAN, C. C. A. S. et al. Organização tópica da conversação. In: ILARI, R. (Org.). Gramática do português falado - v. II: Níveis de análise linguística. Campinas: Editora da UNICAMP, 2002. p. 341-420.

KOCH, I. G. V.; BENTES, A. C.; REZENDE, R. C. Cadernos de Estudos Linguísticos: o Tópico Discursivo, Campinas, v. 48, n. 1, 2006.

PENHAVEL, E. Estudo do processo de estruturação interna de segmentos tópicos mínimos em diferentes gêneros textuais. Projeto de Pesquisa. São José do Rio Preto: Universidade Estadual Paulista, 2013.

PINHEIRO, C. L. Integração de fatos formulativos e interacionais na construção do texto: um estudo a partir da topicalidade. 2003. 421f. Tese (Doutorado em Letras, Filologia e Linguística Portuguesa) - Universidade Estadual Paulista "Júlio de Mesquita Filho", Assis, 2003.

Estratégias textuais-interativas: a articulação tópica. Maceió: EDUFAL, 2005. 